\title{
PENTINGNYA PERAN DAN PENGETAHUAN PERAWAT DALAM PELAKSANAAN TAHAP DIAGNOSA KEPERAWATAN
}

\author{
ANGEL OKTAVIA PURBA / 181101099 \\ angeloktavia013@gmail.com
}

\begin{abstract}
ABSTRAK
Diagnosa keperawatan merupakan suatu pertanyaan yang menggambarkan respons manusia ( keadaan sehat atau perubahan pola interaksi actual/potensial) dari individu atau kelompok. Diagnosa berfungsi untuk mengidentifikasi, memfokuskan, dan memecahkan masalah keperawatan klien secara spesifik. Adapun tujuan dari penulisan ini yaitu agar mengetahui apa itu proses keperawatan, mengetahui apa defenisi diagnose keperawatan, mengetahui apa tujuan dari diagnosa keperawatan, mengetahui apa saja tipe diagnosa keperawatan, mengetahui bagaimana lagkah-langkah menentukan diagnose keperawatan dan mengetahui bagaimana menyusun diagnosa. keperawatan. Metode penulisan ini adalah Literature Riview, dimana ini menganalisis artikel yang relevan dan berfokus pada tema yaitu Diagnosa keperawatan.
\end{abstract}

\begin{abstract}
Nursing diagnosis is a question that describes the human response (healthy state or changes in actual / potential interaction patterns) of individuals or groups. The function of diagnosis is to identify, focus, and solve specific nursing problems of the client. The purpose of this paper is to know what the nursing process is, know what the definition of nursing diagnoses, know what is the purpose of nursing diagnoses, find out what types of nursing diagnoses, find out how the steps determine nursing diagnoses and know how to arrange diagnoses. nursing. This writing method is Riview Literature, where it analyzes relevant articles and focuses on the theme of Nursing Diagnosis.
\end{abstract}

Kata Kunci : Proses Keperawatan, Diagnosa keperawatan, Peran Perawat.

\section{LATAR BELAKANG}

Keperawatan merupakan suatu bentuk layanan kesehatan professional yang merupakan bagian integral dari layanan kesehatan yang berlandaskan ilmu dan kiat keperawatan berbentuk pelayanan yang ditujukan bagi setiap individu, keluarga dan masyarakat. Seiring dengan perkembangan zaman, tentunya

di dalam dunia keperawatan juga semakin berkembang baik dari keilmuan dan praktik keperawatan juga turut berkembang. Begitupun dalam proses keperawatan tentunya juga semakin berkembang. Penerapan proses keperawatan dalam asuhan keperawatan 
untuk klien merupakan salah satu wujud tanggung jawab dan tanggung gugat perawat terhadap klien. Pada akhirnyan, penerapan proses keperawatan ini akan meningkatkan kualitas layanan keperawatan kepada kllien. Dalam proses keperawatan terdapat beberapa tahapan proses keperawatan yaitu pengkajian, diagnose, perencanaan, implementasi dan evaluasi. Setiap tahap proses keperawatan saling terkait dan ketergantungan satu sama lain. Untuk itu dalam memberikan asuhan keperawatan tentunya seorang perawat harus melaksanakan tahap-tahap dalam proses keperawatan tersebut secara benar dan tepat agar tidak terjadi kesalahan sehingga asuhan keperawatan yang diberikan dapat berjalan secara optimal. Tahap yang dilakukan setelah melakukan atau menyelesaikan pengkajian yaitu tahap diagnose dimana pada tahap diagnose merupakan tahap penilaian terhadap masalah kesehatan dan penilaian klinis tentang respon individu, keluarga, atau komunitas mengenai masalah kesehatan . Dalam melaksanakan tahap diagnose sangat dibutuhkan pengetahuan, tanggungjawab dan hal-hal yang dapat mendukung kesehatan pasien. Pada akhirnyan, penerapan proses keperawatan ini akan meningkatkan kualitas layanan keperawatan kepada kllien

\section{TUJUAN}

Adapun tujuan dari penulisan ini yaitu agar mengetahui apa itu proses keperawatan, mengetahui apa defenisi diagnose keperawatan, mengetahui apa tujuan dari diagnosa keperawatan, mengetahui apa saja tipe diagnosa keperawatan, mengetahui bagaimana lagkah-langkah menentukan diagnose keperawatan dan mengetahui bagaimana menyusun diagnosa. keperawatan.

\section{METODE}

Metode penulisan ini adalah Literature Riview, dimana ini menganalisis artikel yang relevan dan berfokus pada tema yaitu Diagnosa keperawatan. Adapun sumber yang digunakan dalam literature ini menggunakan sumber dari buku teks, jurnal dengan memasukan kata kunci Diagnosa dalam proses keperawatan, tipe diagnosa dalam proses keperawatan. Adapun jurnal yang saya yang digunakan merupakan jurnal yang diiterbitkan pada 10 tahun terakhir. 
HASIL

Berdasarkan pencarian literature didapatkan apa itu proses keperawatan, defenisi doagnosa keperawatan dan tujuan dari proses keperawatan. Selain itu juga dapat mengetahui apa saja type diagnosa keperawatan, bagaimana langkah-langkah menentukan diagnosa keperawatan dan bagaimana menyusun diagnose keperawatan.

\section{PEMBAHASAN}

Proses keperawatan adalah suatu pendekatan dalam pemecahan masalah, sehingga perawat dapat merencanakan dan memberikan assuhan keperawatan (Potter \& Perry, 1997). Kemudian menurut Yura Walsh (1983) proses keperawatan adalah suatu tahapan desai tindakan untuk memenuhi tujuan keperawatan. Adapun tujuan proses keperawatan secara umum yaitu adalah membuat kerangka konsep berdasarkan kebutuhan individu atau klien, keluarga dan masyarakat (Carpenito dan Moyet 2007). Dalam proses keperawatan terdapat tahap diagnose keperawatan dimana tahap ini merupakan tahap yang harus dilakukan setelah selesai melakukan tahap pengkajian. Diagnosa keperawatan merupakan suatu pertanyaan yang menggambarkan respons manusia ( keadaan sehat atau perubahan pola interaksi actual/potensial) dari individu atau kelompok. Diagnosa keperawatan adalah pernyataan yang dibuat oleh perawat professional yang memberi gambaran trntang masalah tentang masalah atau status klien, baik actual maupun potensial, yang ditetapkan berdasarkan analisis dan interpretasi dari data hasil pengkajian. Adapun tujuan dari diagnosa yaitu memungkinkan perawat untuk menganalisis dan menyintesis data yang telah dikelompokkan. Selain itu, diagnosa keperawatan digunakan untuk mengidentifikasi masalah, faktor penyebab masalah, dan kemampuan klien untuk dapat mencegah atau memecahkan masalah. Penetapan diagnosa keperawatan berlangsung dalam tiga fase yaitu: 1. Memproses data (Mengorganisasi data, membandingkan data dengan standart nilai norma, mengelompokkan data); 2 . Menentukan masalah keperawatan klien; 3. Menyusun diagnose keperawataan.

Diagnosa berfungsi untuk mengidentifikasi, memfokuskan, dan memecahkan masalah keperawatan klien secara spesifik. Diagnosa 
keperawatan harus benar- benar akurat Karena akan menjadi patokan dalam melaksanakan tindakan keperawatan. Diagnosa keperawatan terdiri atas tiga tipe yaitu diagnosa keperawatan actual, diagnosa keperawatan risiko, dignosa keperawatan sindrom dan diagnose keperawatan sejahtera.

1.Diagnosa keperawatan actual, yaitu diagnose keperawatan yang menjelaskan masalah kesehatan yang nyata terjadi dan benar-benar factual sesuai dengan data klinis yang diperoleh.Syarat untuk menegakkan diagnose keperawatan actual adalah terpenuhinya unsur PES. Komponen diagnose keperawatan actual adalah: a)Label, yaitu perubahan, kerusakan, ketdakefektifan, gangguan,dll. b)defenisi yaitu konseptual dari konsisten dengan label dan batasan karakteristik merupakan arti yang tepat dari diagnosis keperawatan yang sedang terjadi.C)batasan karakteristik, yaitu memnuhi $80 \%$ atau lebih kriterianya mayor. d) faktor yang berhubungan dengan etiologi.

\section{FORMAT: $P+E+S$}

2.Diagnosa keperawatan resiko, yaitu diagnose keperawatan yang menjelaskan masalah kesehatan yang berpeluang besar akan terjadi jika tidak dilakukan tindakan keperawatan. Syarat untuk menegakan diagnosis keperawatan resiko adalah terpenuhinya unsur PES.

\section{FORMAT P + E + S}

3.Diagnosa keperawatan kemungkinan, yaitu pernyataan tentang masalah yang diduga akan terjadi atau masih memerlukan data tambahan. Data tambahan diperlukan untk memastikan adanya tanda/gejala utamaa (actual), faktor resiko, menyampingkan diagnosa.

\section{FORMAT: P+E}

4.Diagnosa keperawatan sindrom, yaitu diagnosis yang terdiri atas kelompok diagnosis keperawatan aktul/resiko yang diperkirakan akan muncul Karen suatu kejadian atau situasi tertentu.

\section{FORMAT: P}

5.Diagnosa keperawatan sejahtera, merupakan keputusan klinis yang divalidasi oleh ungkapan yang" positif" keyika pola fungsi dalam keadaan afektif. P Keputusan klinis tentang keadaan individu, keluarga, atau masyarakat dalam transisi dari tingkat 
sejahtera tertentu ke tingkat sejahtera yang lebih tinggi

\section{FORMAT: atau P+E}

Komponen - komponen dalam pernyataan diagnosis keperawatan meliputi masalah (Problem), penyebab (etiologi), dan data (sign and symptom). Untuk memeudahkannya, disingkat dengan PES.

1.Masalah (problem). Diagnosis keperawatan merupakan perntayaan yang menggambarkan perubahan status kesehatan klien.

\section{Penyebab (etiology). Pernyataan} etiologi mencerminkan penyebab dari masalah kesehatan klien yang memberi arah bagi terapi keperawatan. Etiologi tersebut dapat terkait dengan aspek patofisiologi, psikososial, tingkahlaku, perubahan situasional, gaya hidup,usia perkembangan, juga faktor budaya dan lingkungan.

3.Data (sign and symptom). Data diperoleh selama tahap pengkajian sebagai bukti adanya masalah keehatan pada klien. Data merupakan informasi yang diperlukn untuk merumuskan diagnosis keperawatan.
Beberapa hal yang perlu diperhatikan pada tahap diagnose keperawatan, antara lain : 1. Kesesuaian masalah dengan lingkup keperawatan;. 2.Kejelasan masalah;. 3.Keakuratan masalah dan faktor penyebab; 4.Validasi masalah;. 5. Komponen keperawatan PES.

Adapun cara menentukan diagnosa yaitu dengan menerapkan langkahlangkah untuk menentukan diagnose keperawatan yaitu. Pertama, perawat harus melakukan klasifikasi data. Klasifikasi data adalag aktivitas pengelompokan data-data klien atau keadaan tertentu tempat klien mengalami masalah kesehatan atau keperawatan berdasarkan kriteria permasalahannya. Klasifikasi ini berdasarkan pada kebutuhan dasar manusia yang dikelompokkan dalam data subjektif dan ddata objektif. Kedua, Perawat harus membuat interpretasi data. Perawat bertugas membuat interperetasi atas data yang sudah dikelompokkan dalam bentuk masalaah keperawatan atau masalah kolaboratif. Ketiga, Perawat harus menentukan hubungan sebab-akibat. Dari masalah keperawatan yang telah ditentukan kemudian perawat harus menentukan faktor-faktor yang 
berhubungan atau faktor resiko yang menjadi kemungkinan penyebab dari masalah yang terjadi. Kemungkinan penyebab harus mengacu pada kelompok data yang sudah ada. Keempat, Perawat harus merumuskan diagnose keperawatan. Perumusan diagnose keperawatan yang sudah dibuat berdasarkan pada pola identifikasi masalah dan kemungkinan penyebab.

\section{KESIMPULAN}

Dalam proses keperawatan terdapat tahap diagnose keperawatan dimana tahap ini merupakan tahap yang harus dilakukan setelah selesai melakukan tahap pengkajian. Diagnosa keperawatan merupakan suatu pertanyaan yang menggambarkan respons manusia ( keadaan sehat atau perubahan pola interaksi actual/potensial) dari individu atau kelompok. Diagnosa berfungsi untuk mengidentifikasi, memfokuskan, dan memecahkan masalah keperawatan klien secara spesifik. Langkah-langkah menentukan diagnose keperawatan yaitu perawat harus melakukan klasifikasi data, membuat interpretasi data, menentukan hubungan sebabakibat, dan merumuskan diagnosa keperawatan. Pernyataan diagnosa keperawatan menggunakan pola PROBLEM + ETIOLOGY +SIGN AND SYMPTOM $(\mathrm{P}+\mathrm{E}+\mathrm{S})$. Tipe diagnosa keperawatan terdiri atas: diagnosa keperawatan actual. Diagnosa keperawatan actual, diagnosa keperawatan resiko/resiko tinggi, diagnosis keperawatan kemungkinan, diagnosis keperawatan sindrom dan diagnosis keperawatan sejahtera.

\section{SARAN}

Dalam melaksanakan tugas sebagai pemberi pelayanan kesehatan kepada klien, perawat harus bekerja secara professional dan handal. Selain itu sebagai suatu yang profesional, seorang perawat haarus dibekali dengan ilmu dan pengetahuan yang kuat agar dapat menjalankan tugas dengan baik dan benar.

\section{DAFTAR PUSTAKA}

Ali, Zaidin. (2001). Dasar- Dasar Keperawatan Profesional. Jakarta. Widya Medika.

Asmadi. (2008). Konsep Dasar Keperawatan. Jakarta. EGC. 
Budiono \& Sumirah,B,P.(2016).

Konsep Dasar Keperawatan (Ed 2).

Jakarta. Bumi Medika.

Dermawan, Deden. (2012). Proses

Keperawatan : Penerapan Konsep Dan

Kerangka Kerja. Yogyakarta : Gosyen

Publishing.

Deswani. (2009). Proses Keperawatan dan Berpikir Kritis. Jakarta : Salemba Medika.

Haryanto. (2007). Konsep Dasar Keperawatan Dengan Peemetaan Konsep. Jakarta : Salemba Medika.

Hidayat, A. Aziz Alimut. (2004). Pengantar Konsep Dasar Kepperawatan. Jakarta. Salemba Medika.

Lismidar,H.(1990).Proses

Keperawatan. Jakarta : Universitas Indonesi.

Mangole, J, E. Dkk. (2015). Hubungan Perilaku Perawat Dengan Pendokumentasian Asuhan Keperawatan Di Cardiovascular And Brain Center RSUP. DR.R.D. Kandou
Manado. Jurnal Keperawatan, vol 3 (2).

Potter \& Perry. (2005). Buku Ajar Fundamental Keperawatan Konsep Proses Dan Praktik Edisi 4. Jakarta : EGC.

Potter \& Perry. ( 2010). Fundamental Of Nursing : Edisi 7. Jakarta : EGC.

Rohma, N \& Wahid, S. (2009). Proses Keperawattan. Arruz Media.

Roper, Nancy. (1996). Prinsip-Prinsip Keperawatan. Yogyakarta : Andi Yayasan Essentia Medica.

Setiadi. (2012). Konsep Penulisan Dokumentasi Asuhan Keperawatan. Jakarta. Salemba Medika.

Simamora, R. H. (2009). Dokumentasi keperawatan. Jamber University Press.

Simamora, R. H. ( 2010). Komunikasi Dalam Keperawatan. Jamber University Press. 
Simamora, R. H. (2008). Peran Manajemen Pembinaan Etika Perawat Pelaksanan Dalam Peningkatan Kualitas Pelayanan Asuhan Keperawatan. Jurnal IKESMA.

Tarwoto \& Wartonah. (2012). Kebutuhan Dasar Manusia Dan Proses Keperawatan. Jakarta : Salemba Medika. 